\title{
Growth Medium Constituents Contaminating Mycoplasma Preparations and their Role in the Study of Membrane Glycoproteins in Porcine Mycoplasmas
}

\author{
By J. NICOLET, ${ }^{1 *}$ PH. PAROZ ${ }^{1}$ AND B. KRISTENSEN ${ }^{2}$ \\ Institute of Veterinary Bacteriology ${ }^{1}$ and Institute of Clinical Immunology, Inselspital, ${ }^{2}$ \\ University of Berne, 3012 Berne, Switzerland
}

(Received 15 October 1979; revised 4 January 1980)

\begin{abstract}
Several Mycoplasma and Acholeplasma species chosen at random and solubilized with sodium dodecyl sulphate showed a common periodic acid-Schiff positive band with an apparent molecular weight of about 64000 , when examined by polyacrylamide gel electrophoresis. Another more cathodic minor band was detected in $M$. hyopneumoniae and $M$. flocculare. The common periodic acid-Schiff positive band appeared when a precipitate of serum constituents of the uninoculated growth medium after incubation was examined. The minor band was identified as a serum glycoprotein contaminating mycoplasmas grown in the presence of swine serum. We draw attention to the compounds as a possible source of error in serological tests or in the lymphocyte stimulation response. After lithium diiodosalicylate solubilization and aqueous phenol extraction, polyacrylamide gel electrophoresis showed a periodic acid-Schiff positive band in membranes from $M$. hyopneumoniae (molecular weight 75000) and $M$. hyorhinis (molecular weight 80000), suggesting the presence of a membrane glycoprotein. Such a glycoprotein was absent from $A$. granularum. Since the common periodic acid-Schiff positive band was not extracted by aqueous phenol, this growth medium constituent did not contaminate the preparations of membrane glycoproteins. However, the minor band was present in glycoprotein preparations of $M$. hyopneumoniae grown in the presence of swine serum.
\end{abstract}

\section{INTRODUCTION}

The propagation of mycoplasma cells is usually achieved in complex growth media containing up to $20 \%$ whole animal serum. The absorption of foreign proteins to the mycoplasma surface is a potential hazard. Jordan \& Kulasegaram (1968) reported that Mycoplasma gallisepticum picked up protein from their growth medium. Bradbury \& Jordan (1971) showed that the $\mathrm{pH}$ of the culture medium influenced the adsorption of medium protein to the organisms. Schiefer et al. (1974) suggested that the electron-dense material on the outer membrane of several mycoplasmas may be adsorbed from the growth medium containing blood group substances or yeast extract. In $M$. pneumoniae, Schütten et al. (1978) identified by crossed immunoelectrophoresis two precipitin lines as medium constituents. Using complement fixation and immunodiffusion techniques, Clark et al. (1969) concluded that mycoplasma preparations can carry serum antigens and blood group substances. Williams et al. (1970) reported the non-specific uptake of IgG from the culture medium by $M$. fermentans. Rottem et al. (1973) found that at $\mathrm{pH}$ values below 5 a large amount of serum albumin was bound to Acholeplasma laidlawii cell membranes. By immunizing a rabbit with $M$. gallisepticum, Bradbury \& Jordan (1972) found antibodies to growth medium serum constituents, particularly to immunoglobulins, transferrin and a prealbumin. When examining the electrophoretic pattern of various mycoplasmas by poly- 
acrylamide gel electrophoresis (Paroz et al., 1976), we observed at least two fractions common to all Mycoplasma and Acholeplasma species studied, suggesting a contamination from the growth medium. Staining of the gel with periodic acid-Schiff reagent (PAS) revealed PAS-positive bands (Paroz \& Nicolet, 1978) which may be misinterpreted as mycoplasma membrane glycoproteins.

The presence of genuine glycoproteins in the membrane of mycoplasmas was first recognized in $M$. pneumoniae by Kahane \& Marchesi (1973) who postulated a structure and localization similar to that seen in red blood cells. Goel \& Lemcke (1975) succeeded in isolating and characterizing a glycoprotein fraction from membranes of $M$. gallisepticum. The presence of a membrane glycoprotein was also suspected in $M$. hominis (Hollingdale \& Lemcke, 1972); the authors suggested, however, that this component could be a peptide with periodate-sensitive amino acids. Johansson (1978) reported the isolation of a glycoprotein in $A$. laidlawii with a molecular weight of 140000 which had antigenic determinants exposed on the cytoplasmic face of the membrane. Recently, Kahane \& Brunner (1977) isolated a glycoprotein with an apparent molecular weight of about 60000 from the membrane of $M$. pneumoniae.

The aim of the present study was to define the properties of the PAS-positive fractions of the growth medium contaminating mycoplasma preparations and to distinguish them from glycoproteins which were obtained after aqueous phenol extraction of mycoplasma membrane preparations.

\section{METHODS}

Organisms. The following Mycoplasma strains were used. Human strains: M. hominis PG 21 (H 50) and $M$. pneumoniae FH. Bovine strains: $M$. mycoides subsp. mycoides PG 1, $M$. bovigenitalium PG 11 (B 2), $M$. bovirhinis PG 43 (5 M 331), M. bovis Donetta (PG 45), M. dispar 462/2, M. bovoculi M 165/69, M. alkalescens D 12 (PG 51) and $M$. verecundum. Caprine and ovine strains: $M$. mycoides subsp. capri PG 3, $M$. agalactiae subsp. agalactiae PG 2, M. conjunctivae HRC 581, M. arginini G 230, M. capricolum California Kid, M. putrefaciens KS-1 and M. ovipneumoniae Y 98. Porcine strains: $M$. hyorhinis BTS-7, M. hyopneumoniae JF 184 (kindly supplied by P. Whittlestone, School of Veterinary Medicine, Cambridge), M. hyosynoviae S 16 and $M$. flocculare Ms 42 (kindly supplied by N. F. Friis, Royal Veterinary and Agricultural University, Copenhagen, Denmark). Rodent strain: M. pulmonis Ash (PG 34).

Acholeplasma strains used were: A. laidlawii PG 8 (Sewage a), A. granularum BTS-39, A. axanthum S-743, A. modicum Squire (PG 49) and A. oculi $19 \mathrm{~L}$.

All Mycoplasma and Acholeplasma strains except $M$. hyopneumoniae and $M$. flocculare were kindly supplied by Professor E. A. Freundt, FAO/WHO Collaborating Centre for Animal Mycoplasmas, Institute of Medical Microbiology, University of Aarhus, Denmark.

Media. Goodwin-Whittlestone medium (Goodwin et al., 1965) was used for the propagation of M. hyopneumoniae; this contains $30 \%$ (v/v) Hartley's digest broth (Oxoid PM1185), $20 \%$ (v/v) pig serum, $0.5 \%$ (w/v) lactalbumin hydrolysate (Difco), $50 \%$ (v/v) Hanks balanced salt solution (Oxoid BR19) and $0.05 \%$ (w/v) yeast extract (Fleischman's active dry yeast).

Friis medium (Friis, 1971) used for the propagation of $M$. flocculare contains both horse and pig serum.

Bern medium (Bannerman \& Nicolet, 1971) was used for propagating all other mycoplasmas examined; this contains PPLO medium (Difco) enriched with $20 \%(\mathrm{v} / \mathrm{v})$ horse serum, $2.5 \%(\mathrm{w} / \mathrm{v})$ yeast extract (Fleischman's active dry yeast), $1 \%(\mathrm{w} / \mathrm{v})$ glucose and $0.005 \% \mathrm{DNA}$.

To reduce contamination with growth medium constituents (for the lymphocyte stimulation assay), sterile whole serum was preincubated for $5 \mathrm{~d}$ at $37^{\circ} \mathrm{C}$ and centrifuged at $20000 \mathrm{~g}$ before addition to the growth medium.

Culture conditions. All broth cultures were incubated at $37^{\circ} \mathrm{C}$ without shaking, except $M$. hyopneumoniae which was shaken at $70 \mathrm{rev} . \mathrm{min}^{-1}$. Cells were harvested in the exponential phase of growth; in the case of glucose-fermenting strains the $\mathrm{pH}$ of the medium was about 6.8 to 7.0 at harvest. The cells were thoroughly washed three times in $0.25 \mathrm{M}-\mathrm{NaCl}$ by centrifugation at $20000 \mathrm{~g}$ for $20 \mathrm{~min}$ at $4{ }^{\circ} \mathrm{C}$. The resuspended cells were designated as whole cells or were used for membrane preparation. Mycoplasma pneumoniae was grown on the surface of a plastic tissue culture flask and harvested as described by Kahane \& Brunner (1977).

Sodium dodecyl sulphate $(S D S)$ solubilization. Whole cells, membranes or serum precipitate were solubilized with $12.5 \mathrm{mM}$-phosphate buffer $\mathrm{pH} 7.2$ containing $1 \%(\mathrm{w} / \mathrm{v})$ SDS and $1 \%(\mathrm{w} / \mathrm{v}) \beta$-mercaptoethanol [1 $\mathrm{ml}$ ( $\mathrm{mg}$ cell protein) $\left.{ }^{-1}\right]$ and boiled for $3 \mathrm{~min}$, as described previously (Paroz et al., 1976). 
Isolation of cell membranes. Two procedures described by Razin \& Rottem (1976) were used: osmotic lysis in deionized water for A. granularum and digitonin lysis for M. hyopneumoniae, M. hyorhinis and M. pneumoniae. To prevent contamination with ribosomes and DNA, the washed membrane suspensions were treated with RNAase and DNAase (Serva) for $15 \mathrm{~min}$ at $37^{\circ} \mathrm{C}$ and after washing were resuspended in $1 / 20$ diluted $\beta$-buffer (Razin \& Rottem, 1976).

Extraction of membrane glycoprotein. Kahane \& Brunner's (1977) modification of the procedure described by Marchesi \& Andrews (1971) was followed, i.e. treatment with lithium diiodosalicylate and subsequent extraction with fresh aqueous phenol and delipidation with chloroform/methanol.

$S D S$-polyacrylamide gel electrophoresis. We used the phosphate-buffered $7.5 \%(\mathrm{w} / \mathrm{v})$ gel system described by Morowitz \& Terry (1969), containing $1 \%$ (w/v) SDS, with the flat gel slab method in an apparatus from Biowerk (Biozentrum, Basel, Switzerland). Samples (20 to $40 \mu \mathrm{l}$ containing $1 \mathrm{mg}$ cell protein $\mathrm{ml}^{-1}$ ) were layered with $30 \%(\mathrm{v} / \mathrm{v})$ glycerol and subjected to electrophoresis. The slabs were stained for proteins with Coomassie Brilliant Blue R (Chrambach et al., 1967) and for glycoproteins with the periodic acid-Schiff reagent by the method described by Zacharius et al. (1969). To reveal membrane glycoproteins better the following modification was used. Immediately after electrophoresis the gels were immersed in $12.5 \%(\mathrm{w} / \mathrm{v})$ trichloroacetic acid for $45 \mathrm{~min}$ and then oxidized with $0.8 \%(\mathrm{w} / \mathrm{v})$ periodic acid for $3 \mathrm{~h}$. The gels were then washed by shaking 10 times for $10 \mathrm{~min}$ with water. These steps were all carried out at room temperature. The gels were then immersed in freshly prepared Schiff reagent and stored in the dark at $4{ }^{\circ} \mathrm{C}$ for $10 \mathrm{~h}$. Subsequently, they were rinsed three times for $10 \mathrm{~min}$ in $0.5 \%(\mathrm{w} / \mathrm{v})$ sodium metabisulphite in the dark and three times for $10 \mathrm{~min}$ with water in the light. The gels were preserved in sodium metabisulphite.

Molecular weight determination. Apparent molecular weight was determined by comparing the electrophoretic mobility with a standard calibration curve constructed by running in parallel a low molecular weight calibration kit (Pharmacia).

Chemical analyses. Protein content was measured by the Hartree (1972) modification of the Lowry method, using bovine serum albumin as the standard. Carbohydrates were estimated by measuring total hexose using the anthrone procedure (Troy et al., 1953) with galactose as standard. Phospholipid content was determined as described by Bartlett (1958).

Immunization of rabbits. Young rabbits weighing 2 to $3 \mathrm{~kg}$ were immunized with washed mycoplasma suspensions or serum precipitates mixed with an equal volume of complete Freund's adjuvant according to the schedule described previously (Bannerman \& Nicolet, 1971).

Double-diffusion test. The test was performed by the method of Ouchterlony (1967) in its micro-modification. An agarose layer $(0.5 \mathrm{~mm})$ was poured with the use of a matrix on precleaned slides. A $6 \mathrm{~mm}$ thick plastic block with six peripheral conical holes and one central hole of $1 \mathrm{~mm}$ diameter was then applied to the agarose and the wells were filled with antiserum or antigen. Optimal precipitin lines were detected after $48 \mathrm{~h}$ incubation at room temperature in a moist chamber.

Lymphocyte stimulation. The technique used was based on that described by Lazary et al. (1974), with the following modifications: pig lymphocytes were isolated from peripheral blood by centrifugation on a Ficoll-isopaque gradient (Ficoll-isopaque, 400) and cultured in a micro-tissue culture plate (Micro Test II TM, Falcon, Oxnard). The results were reported as counts $\mathrm{min}^{-1}$ or, for purposes of comparison, as stimulation index (SI).

Affinity chromatography on concanavalin A-Sepharose. Affinity chromatography was carried out using concanavalin A-Sepharose gel (Pharmacia) in a column (K 16/20, Pharmacia) with a bed volume of $2.2 \mathrm{ml}$. The gel was equilibrated with $0.025 \mathrm{M}-\mathrm{Tris} / \mathrm{HCl}$ buffer, $\mathrm{pH} 7 \cdot 2$, containing $0.2 \mathrm{M}-\mathrm{NaCl}$ at a flow rate of 4.2 $\mathrm{ml} \mathrm{h}^{-1}$. After application of $1.8 \mathrm{ml}$ horse or swine serum, unbound protein was eluted with the same buffer, and elution of adsorbed material was achieved by including $0.3 \mathrm{M}$-methyl- $\alpha$-D-mannoside (Fluka, Buchs, Switzerland) in the buffer. Fractions $(1 \mathrm{ml})$ were collected in a LKB 7000 Ultrarac fraction collector. For processing a greater amount of serum $(60 \mathrm{ml})$, we used a larger column (K 50/60, Pharmacia) with a bed volume of $230 \mathrm{ml}$ and a flow rate of $30 \mathrm{ml} \mathrm{h}^{-1}$.

\section{RESULTS}

\section{Electrophoretic pattern of SDS-solubilized whole cells and membranes}

All strains listed in Methods were submitted to polyacrylamide gel electrophoresis. The protein pattern of a random selection of mycoplasmas from different origins is illustrated in Fig. 1(a). The overall picture is specific for each species, but two fractions (arrowed) seem to have similar migration patterns in all the strains examined.

Staining the gels with periodic acid-Schiff reagent (PAS) showed that a common broad 

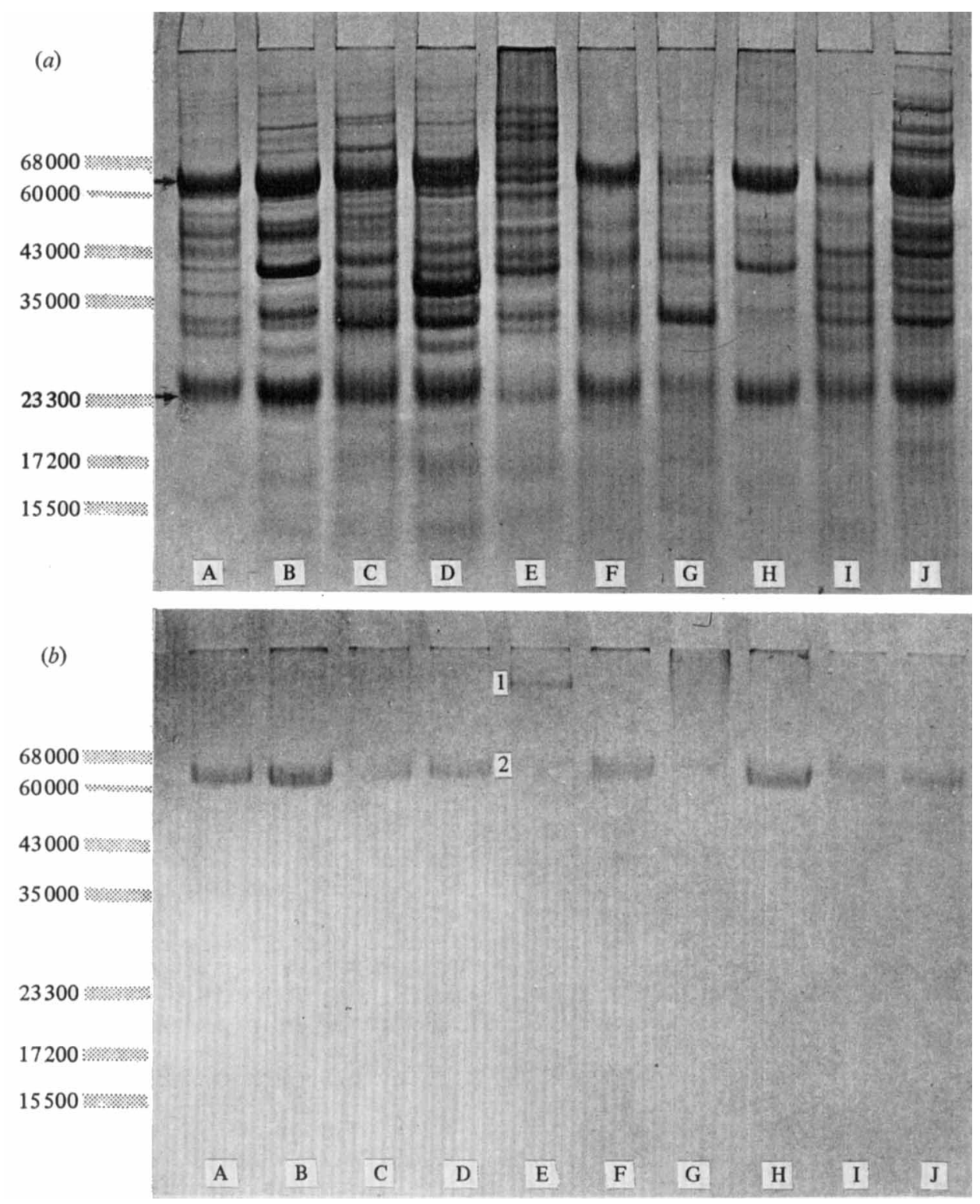

Fig. 1. Flat gel SDS-polyacrylamide electrophoresis of SDS-solubilized whole cells of various mycoplasmas. (a) Protein pattern: Coomassie Blue stain (arrows indicate fractions with similar migration). (b) Periodic acid-Schiff reagent (1, minor band; 2, common band). A, M. pneumoniae; B, $M$. hominis; C, M. ovipneumoniae; D, M. agalactiae subsp. agalactiae; E, M. hyopneumoniae; F, M. hyorhinis; G, M. mycoides subsp. mycoides; H, M. arginini; I, M. bovis; J, M. pulmonis. Positions of bands from molecular weight standards are shown on the left.

PAS-positive band with a similar mobility, but with some differences in intensity, was obtained with all strains tested (Fig. 1b). A minor PAS-positive band was detected only in $M$. hyopneumoniae and $M$. flocculare.

Preparation of membranes by osmotic or digitonin lysis with subsequent SDS-solubilization eliminated neither the common broad PAS-positive band nor the minor band of $M$. hyopneumoniae. 


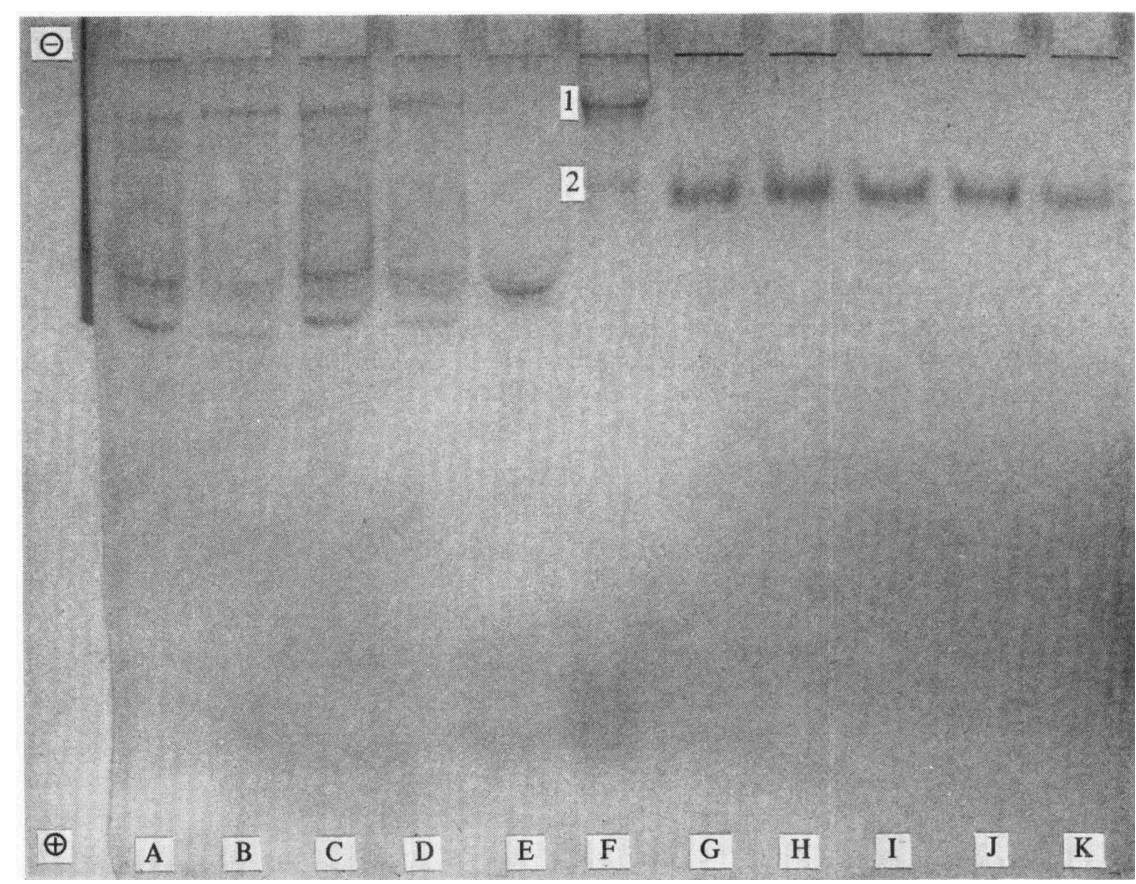

Fig. 2. Flat gel SDS-polyacrylamide electrophoresis, stained with periodic acid-Schiff reagent. Comparison between fresh growth media or serum and serum precipitates sedimented at $20000 \mathrm{~g}$ and $M$. hyopneumoniae (1, minor band; 2, common band). A, Goodwin-Whittlestone medium; B, Bern medium; C, swine serum; D, horse serum; E, PPLO serum fraction (Difco); F, M. hyopneumoniae (SDS-solubilized whole cells grown in A); G, serum precipitate from Goodwin-Whittlestone medium; H, serum precipitate from Bern medium; I, serum precipitate from swine serum; $J$, serum precipitate from horse serum; K, serum precipitate from PPLO serum fraction.

\section{Electrophoretic pattern of growth media and serum constituents}

In the search for contamination of our mycoplasma preparations by growth medium constituents, we investigated the electrophoretic pattern of different uninoculated fresh growth media and of horse and swine sera. With the exception of the minor band, which seems to be similar to that seen in the mycoplasma preparations grown in media containing swine serum, the growth media (Fig. 2A, B), whole sera (Fig. 2C, D) and PPLO serum fraction (Fig. 2E) (Difco) all had PAS-positive bands that migrated at a different rate from those found in the mycoplasma preparations (Fig. 1b, Fig. 2F). Furthermore, when uninoculated growth media, or sera (swine, horse or PPLO serum fraction) were incubated for a few days at $37^{\circ} \mathrm{C}$ and the barely visible precipitates sedimented at $20000 \mathrm{~g}$ were dissolved in SDS, the preparations gave a common PAS band (Fig. $2 \mathrm{G}$ to $\mathrm{K}$ ) similar to that observed in the mycoplasma preparations.

\section{Properties of the common PAS-positive band}

The common PAS-positive band from precipitates also migrated as a single band shown by Coomassie Blue staining. Comparison of the mobility of this band and those of standard proteins gave an apparent molecular weight of 64000 . The gross chemical analysis of the precipitates indicated that they consisted of proteins $(40 \%)$ and phospholipids $(60 \%)$. Carbohydrates were also present, as indicated by the PAS stain, but no quantitative analysis was made. 

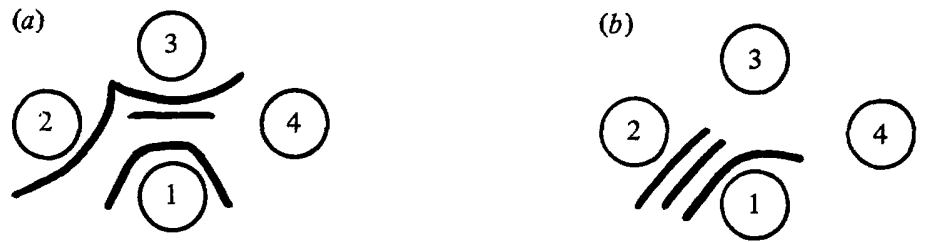

Fig. 3. Agar gel diffusion patterns. (a) 1, Antiserum to precipitates from swine serum; $2, M$. hyopneumoniae grown in Goodwin-Whittlestone medium (swine serum); 3, precipitates from swine serum; 4, M. hyorhinis grown in Bern medium (horse serum). (b) 1 , Precipitates from swine serum; 2 , antiserum to precipitates from swine serum; 3 , antiserum to swine IgG; 4 , antiserum to horse IgG.

\section{Effect of the common PAS-positive band on serological investigation}

A double-diffusion test between antiserum to swine serum precipitates and $M$. hyopneumoniae, $M$. hyorhinis and swine serum precipitates as antigens gave at least three precipitin lines. One of these lines was common to $M$. hyopneumoniae and serum precipitates, the second was specific for serum precipitates and the third was common to all three antigens tested. This suggests that at least two of the serum precipitate antigens contaminate the $M$. hyopneumoniae preparation (growth medium containing swine serum) and one of them cross-reacts with a $M$. hyorhinis preparation grown in a medium containing horse serum (Fig. $3 a$ ). Moreover, Fig. 3(b) indicates that the swine serum precipitate contained swine IgG that did not cross-react with anti-horse IgG.

\section{Removal of the serum precipitates}

Passage of sera through a concanavalin A-Sepharose column for elimination of the glycoproteins removed, among others, the minor PAS band, but did not prevent the formation of the common band after incubation. Additionally, such sera depleted of glycoproteins no longer permitted the growth of mycoplasmas. Attempts to adapt $M$. hyopneumoniae to growth in a medium containing serum from colostrum-deprived new-born piglets failed. We finally removed quantitatively the common PAS-positive band by incubating the whole sterile serum for $5 \mathrm{~d}$ at $37^{\circ} \mathrm{C}$ and centrifuging at $20000 \mathrm{~g}$ before adding it to the growth medium. The minor PAS-positive band, however, was not eliminated by this procedure.

\section{Effect on lymphocyte stimulation assay}

The blastogenic effect of $M$. hyopneumoniae grown in a medium with preincubated and centrifuged serum was significantly lower than with antigen contaminated with serum precipitates (Table 1).

\section{Demonstration of membrane glycoproteins after treatment with lithium diiodosalicylate and aqueous phenol extraction}

The electrophoretic pattern after extraction of the membrane glycoproteins from $M$. hyopneumoniae, $M$. hyorhinis and A. granularum is shown in Fig. 4, together with the whole peptide pattern of SDS-solubilized cells of $M$. hyopneumoniae. The extracted fractions of $M$. hyopneumoniae revealed two bands with $R_{F}$ values of 0.08 (molecular weight $>94000$ ) and $0 \cdot 3$ (molecular weight 75000 ; mean from several runs). The extract of membranes of $M$. hyorhinis revealed only one peptide with an $R_{F}$ value of 0.33 (molecular weight 80000 ). In both strains the PAS stain (modified) showed a band with a pattern similar to the one given with Coomassie Blue protein stain. 
Table 1. Blastogenic effect of $M$. hyopneumoniae antigens on peripheral blood lymphocytes of pigs

Whole cell antigen was cultured in medium pre-incubated at $37^{\circ} \mathrm{C}$ for $5 \mathrm{~d}$ and centrifuged at $20000 \mathrm{~g}$ (without contaminants) or under conditions described in Methods (with contaminants). The results are expressed as counts min $^{-1}$ (mean values of triplicate cultures) \pm standard deviation and as stimulation index (SI) calculated relative to unstimulated lymphocytes. For comparison, the results of the stimulation of lymphocytes with phytohaemagglutinin P (PHAP) are given.

\begin{tabular}{|c|c|c|c|c|c|c|}
\hline \multirow{2}{*}{$\begin{array}{c}\text { Animal } \\
\text { no. }\end{array}$} & \multirow{2}{*}{$\begin{array}{l}\text { Unstimulated } \\
\text { cultures }\end{array}$} & \multicolumn{2}{|c|}{$\begin{array}{l}\text { Cultures stimulated with } \\
\left.\text { antigen ( } 20 \mu \mathrm{g} \mathrm{ml}^{-1}\right) \\
\text { (without contaminants) }\end{array}$} & \multicolumn{2}{|c|}{$\begin{array}{l}\text { Cultures stimulated with } \\
\text { antigen }\left(20 \mu \mathrm{g} \mathrm{ml}^{-1}\right) \\
\text { (with contaminants) }\end{array}$} & \multirow{2}{*}{$\begin{array}{c}\text { Cultures } \\
\text { stimulated } \\
\text { with PHAP } \\
(8 \mu \mathrm{g} \text { protein } \\
\left.\mathrm{ml}^{-1}\right)\end{array}$} \\
\hline & & Counts $\min ^{-1}$ & SI & Counts $\min ^{-1}$ & SI & \\
\hline $3394^{*}$ & $7312 \pm 2016$ & $6797 \pm 309$ & 0.9 & $12603 \pm 911$ & $1 \cdot 7$ & $54297 \pm 11290$ \\
\hline $3395 \dagger$ & $5916 \pm 594$ & $9259 \pm 2546$ & $1 \cdot 6$ & $36414 \pm 5088$ & $6 \cdot 2$ & $64429 \pm 5061$ \\
\hline $3396 \dagger$ & $2251 \pm 838$ & $7671 \pm 1051$ & 3.4 & $10412 \pm 1552$ & $4 \cdot 6$ & $57672 \pm 10525$ \\
\hline $3397 \dagger$ & $761 \pm 247$ & $2407 \pm 473$ & $3 \cdot 2$ & $6048 \pm 966$ & $7 \cdot 9$ & $63062 \pm 6327$ \\
\hline $3398 \dagger$ & $1188 \pm 247$ & $465 \pm 130$ & 0.4 & $907 \pm 253$ & 0.8 & $46565 \pm 8164$ \\
\hline $3399 \dagger$ & $3545 \pm 334$ & $1836 \pm 505$ & 0.5 & $4840 \pm 226$ & 1.4 & $64338 \pm 10159$ \\
\hline $3400^{*}$ & $614 \pm 57$ & $538 \pm 144$ & 0.9 & $874 \pm 132$ & 1.4 & $69776 \pm 8350$ \\
\hline $3401^{*}$ & $1390 \pm 1077$ & $2014 \pm 361$ & $1 \cdot 4$ & $6159 \pm 619$ & $4 \cdot 4$ & $71080 \pm 11806$ \\
\hline
\end{tabular}

* Pigs vaccinated with a $M$. hyopneumoniae vaccine in Freund's adjuvant.

$\dagger$ Spontaneous infection with $M$. hyopneumoniae.

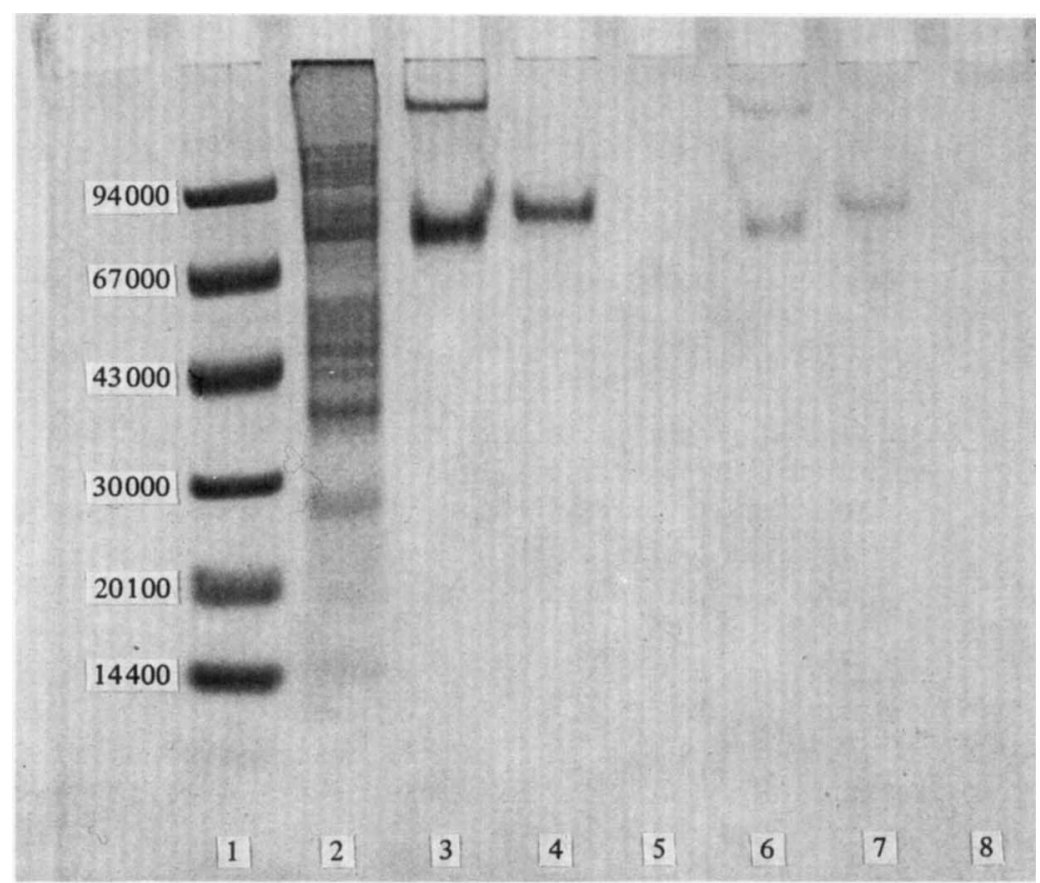

Fig. 4. Flat gel SDS-polyacrylamide gel electrophoresis, stained with Coomassie Blue (1 to 5$)$ or with the periodic acid-Schiff reagent (6 ta 8). 1, Molecular weight standards; $2, M$. hyopneumoniae (SDS-solubilized whole cells). Membrane glycoprotein extracts from: 3 and 6, M. hyopneumoniae; 4 and 7, M. hyorhinis; 5 and 8, A. granularum.

For comparison, we examined the membrane glycoprotein of $M$. pneumoniae according to the method of Kahane \& Brunner (1977). A single band corresponding to a molecular weight, estimated in our gel system, of 65000 , was obtained with both stains. Using the same extraction procedure and applying a tenfold higher concentration, no peptide band was observed in the $A$. granularum membrane extract. This shows, at least, that the common PAS-positive band as a growth medium contaminant was not extracted by this method. 
The carbohydrate component of the extracted membrane glycoproteins was estimated as $230 \mu \mathrm{g}$ (mg protein) $)^{-1}(23 \%)$ for $M$. hyopneumoniae and $110 \mu \mathrm{g}$ (mg protein) ${ }^{-1}(11 \%)$ for M. hyorhinis.

Aqueous phenol extraction of growth medium precipitates did not show any bands; extraction of whole pig serum, however, showed the presence of a minor band with a molecular weight of more than 94000 , similar to that observed in SDS-solubilized whole cells of $M$. hyopneumoniae and $M$. flocculare.

\section{DISCUSSION}

The fact that mycoplasmas grown in vitro may be contaminated by constituents of the growth medium is well known. Few reports, however, have dealt with the nature of these contaminants. During an investigation of membrane glycoproteins of different mycoplasma preparations we observed that whole cells or membranes solubilized with SDS showed, after polyacrylamide gel electrophoresis and PAS staining, at least one common broad PAS-positive band (Fig. $1 b$ ) with a molecular weight estimated at 64000 . Since this band was not evident in fresh growth media and whole sera (Fig. 2A to E), we concluded that some serum constituents precipitated during prolonged incubation (Fig. $2 \mathrm{G}$ to $\mathrm{K}$ ).

The chemical nature of such precipitates, including the presence of carbohydrates (PAS stain), protein $(40 \%)$, phospholipids $(60 \%)$ and $\mathrm{IgG}$, suggested a complex from different serum constituents, among them lipoproteins, possibly glycolipids and/or aggregates of glycoproteins.

Another PAS-positive growth medium constituent, designated as the minor band, has been identified as a glycoprotein present in serum (Fig. 2A to D) and as a contaminant of mycoplasma cultures grown in swine serum (Fig. 1b, Fig. 2F). Since this minor band seemed to be present in the whole horse serum as well (Fig. 2D), but not in the different precipitates (Fig. $2 \mathrm{G}$ to $\mathrm{K}$ ), it appeared that this fraction in swine serum has a certain affinity for the mycoplasma surface. Preliminary results obtained by ultracentrifugation in a sucrose density gradient confirmed this hypothesis. The presence of such contaminants is obviously highly undesirable; it leads, for instance, to confusing serological cross-reactions, at least with rabbit antisera (Fig. 3), and to enhancement of the blastogenic effect of antigens used in the lymphocyte transformation assay (Table 1).

Attempts to eliminate the contaminating serum constituents by chromatographic methods were not successful. At present the only way to eliminate these contaminants effectively is to preincubate the whole sterile serum (or serum fraction) and to discard the precipitate obtained after centrifugation.

In the study of membrane glycoproteins using aqueous phenol extraction these growth medium contaminants are of less importance. The common PAS-positive band was not extracted by this method, confirmation being afforded by the lack of bands in $A$. granularum extracts (Fig. 4). However, the minor PAS-positive band shown in M. hyopneumoniae (Fig. 4) may be a glycoprotein from the swine serum contained in the growth medium and extractable by aqueous phenol. Bearing in mind these considerations, we suggest that the bands revealed by Coomassie Blue and PAS stains after aqueous phenol extraction with molecular weights of 75000 for $M$. hyopneumoniae and 80000 for $M$. hyorhinis are genuine membrane glycoproteins.

For comparison, we confirmed the observations of Kahane \& Brunner (1977) with $M$. pneumoniae, except that in our gel system the molecular weight appeared to be 65000 . This suggested a varying chemical structure for these mycoplasma membrane glycoproteins. Unfortunately, no support for this hypothesis is provided by the carbohydrate composition, since the higher content of $M$. hyopneumoniae may be due to the contamination by the swine serum glycoprotein.

The variability of the intensity of the PAS-stained band is a major problem in detecting 
the carbohydrate content of the extracted band. With $M$. pneumoniae we did not encounter real difficulties. However, with $M$. hyopneumoniae and $M$. hyorhinis we found that the gel wash and oxidation conditions could be modified to ensure that the removal of periodic acid was complete without allowing any significant loss of PAS-staining material through sample solubilization because of the reversibility of fixation with trichloroacetic acid (Kapitany \& Zebrowski, 1973). Kahane \& Brunner (1977) further suggest that carbohydrate content may vary with the age of the culture.

Although we cannot yet achieve a more complete chemical characterization of the glycoproteins observed in the porcine strains of mycoplasma, we nevertheless confirm similar observations recorded for M. pneumoniae (Kahane \& Marchesi, 1973), M. gallisepticum (Goel \& Lemcke, 1975) and M. hominis (Hollingdale \& Lemcke, 1972), including the lack of such a membrane component in Acholeplasma (Kahane \& Brunner, 1977). We certainly cannot offer more proof in favour of the fact that we are dealing with true glycoproteins which are rare constituents of prokaryote membranes, but we refer to the very convincing arguments offered by Kahane \& Brunner (1977).

This investigation was supported by grant no. 3.036.076 of the Swiss National Foundation for Scientific Research.

\section{REFERENCES}

BanNerman, E. \& NiCOlet, J. (1971). Isolation and identification of porcine mycoplasma in Switzerland. Schweizer Archiv für Tierheilkunde 113, 697-710.

Bartlett, R. (1958). Phosphorus assay in column chromatography. Journal of Biological Chemistry 234, 466-471.

Bradbury, J. M. \& Jordan, F. T. W. (1971). The adsorption of gamma-globulins to Mycoplasma gallisepticum and the possible role in non-specific serological reactions. Veterinary Record 89, 318.

Bradbury, J. M. \& Jordan, F. T. W. (1972). Studies on the adsorption of certain medium proteins to Mycoplasma gallisepticum and their influence on agglutination and haemagglutination. Journal of Hygiene 70, 267-278.

Chrambach, A., Reisfeld, R. A., Wyckoff, M. \& ZACCARI, J. (1967). A procedure for rapid and sensitive staining of protein fractionated by polyacrylamide gel electrophoresis. Analytical Biochemistry 20, 150-154.

Clark, H. W., Baily, J. S. \& MCBrown, T. (1969). Variations on mycoplasma antigenic activity. In Mycoplasma Diseases of Man, Proceedings of an International Symposium, Reinhardsbrunn Castle. Edited by M. Sprössig \& W. Witzleb. Jena: Gustav Fischer.

FrIIS, N. F. (1971). Mycoplasmas cultivated from the respiratory tract of Danish pigs. Acta veterinaria scandinavica 12, 69-79.

Goel, M. C. \& LemCKe, R. M. (1975). Dissociation of Mycoplasma gallisepticum membranes with lithium diiodosalicylate and isolation of a glycoprotein. Annales de Microbiologie 126B, 299312.

Goodwin, R. F. W., Pomeroy, A. P. \& WhittleSTONE, P. (1965). Production of enzootic pneumonia in pigs with a mycoplasma. Veterinary Record 77, 1247-1249.

HARTREe, E. F. (1972). Determination of protein; a modification of the Lowry method that gives a lin- ear photometric response. Analytical Biochemistry 48, 422-427.

Hollingdale, M. R. \& Lemcke, R. M. (1972). Membrane antigens of Mycoplasma hominis. Journal of Hygiene 70, 85-98.

Johansson, K. E. (1978). Production and utilization of monospecific antisera against membrane proteins from Acholeplasma laidlawii. Zentralblatt für Bakteriologie, Parasitenkunde, Infektionskrankheiten und Hygiene (Abteilung I, Originale A) 241, 199-200.

Jordan, F. T. W. \& Kulasegaram, P. (1968). Non-specific antibodies in chickens inoculated intratracheally with Mycoplasma gallisepticum. Journal of Comparative Pathology 78, 407.

KAHANE, I. \& BRUNNER, H. (1977). Isolation of a glycoprotein from Mycoplasma pneumoniae membranes. Infection and Immunity 18, 273-277.

KaHANE, I. \& Marchesi, V. T. (1973). Studies on the orientation of proteins in mycoplasma and erythrocyte membranes. Annals of the New York Academy of Sciences 225, 38-45.

Kapitany, R. A. \& Zebrowski, E. J. (1973). A high resolution PAS stain for polyacrylamide gel electrophoresis. Analytical Biochemistry 56, 361-369.

LazARY, S., Rivera, E., DE WeCK, A. L., Gerber, H. \& NiCOLET, J. (1974). In vitro stimulation of bovine leucocytes by phytohaemagglutinin and other mitogens. Research in Veterinary Science 17, 344-350.

Marchesi, V. T. \& Andrews, E. P. (1971). Glycoproteins: isolation from cell membranes with lithium diiodosalicylate. Science 174, 1247-1248.

Morowitz, H. J. \& TERRY, T. M. (1969). Characterization of the plasma membrane of Mycoplasma laidlawii. Biochimica et biophysica acta 183, 276294.

OUCHTERLONY, O. (1967). Immunodiffusion and immunoelectrophoresis. In Handbook of Experimental Immunology, pp. 655-706. Edited by D. M. Weir. Oxford: Blackwell Scientific Publications. 
Paroz, Ph. \& Nicolet, J. (1978). Glycoproteins in mycoplasmas. Contamination with serum aggregates from growth media. Experientia 34, 1668. Paroz, Ph., KRawinkler, M. \& Nicolet, J. (1976). Verwendung der Polyacrylamid-GelElektrophorese in der Diagnostik von NutztierMycoplasmen. Zentralblatt für Veterinärmedizin, B 24, 668-677.

RAzIN, S. \& RotTem, S. (1976). Techniques for the manipulation of mycoplasma membranes. In Biochemical Analysis of Membranes, pp. 3-26. Edited by A. H. Maddy. London: Chapman and Hall.

RotTeM, S., Hasin, M. \& RaziN, S. (1973). Binding of proteins to mycoplasma membranes. Biochimica et biophysica acta 298, 876-886.

Schiefer, H. G., Gerhardt, U., BrunNer, H. \& KRUPE, M. (1974). Studies with lectins on the surface carbohydrate structure of mycoplasma membranes. Journal of Bacteriology 120, 81-88.
Schütten, H. J., Mogensen, H. H. \& Lind, K. (1978). Mycoplasma pneumoniae antigens demonstrated by crossed immunoelectrophoresis. Zentralblatt für Bakteriologie, Parasitenkunde, Infektionskrankheiten und Hygiene (Abteilung I, Originale A) 241, 240.

Troy, A., Scott, J. \& Melvin, E. (1953). Determination of dextran with anthrone. Analytical Chemistry 25, 1656-1661.

Williams, M. H., Brostoff, J. \& Roitt, J. M. (1970). Possible role of Mycoplasma fermentans in pathogenesis of rheumatoid arthritis. Lancet 2, 277-288.

Zacharius, R. M., Zell, T. E., Morrison, J. H. \& WoodLOCK, J. J. (1969). Glycoprotein staining following electrophoresis on acrylamide gels. Analytical Biochemistry 30, 148-152. 